\title{
COMPARATIVE STUDY ON DIFFERENT TYPES OF REGRESSION APPLIED TO UNEMPLOYMENT IN MARAMURES COUNTY OF ROMANIA
}

\author{
Magnolia Tilca \\ "Vasile Goldis" Western University of Arad \\ e-mail: tilca.magnolia@uvvg.ro \\ Meda Bojor \\ "Gheorghe Sincai" National College Baia Mare
}

(Received May 2016; Accepted July 2016)

\begin{abstract}
We are studying the economic phenomenon of the unemployment in Maramures County of Romania. To obtain plausible conclusions regarding this study we apply different types of regression: the linear regression, polynomial regression, spline and Bspline regression. In this paper we focus on the numerical side of the research and we compare the predicted values, the graphic representation of the evolution, the future predictions and the errors generated by the regressions mentioned above. The calculations are performed in $\mathrm{R}$, a programming language for statistical computing. An implementation in $\mathrm{R}$ is given.
\end{abstract}

Keywords: linear regression, splines regression, B-spline regression, $\mathrm{R}$ language, the evolution of the unemployment in Maramures

J.E.L. CODES: C68, R15

\section{Introduction}

National and County Employment Agencies (ANOFM and AJOFM), together with the National Statistical Institute of Romania (INSR), study the evolution of unemployment in Romania using statistical methods that compare the number of unemployed relative to unit time, relative to the region, educational studies, sex, age or unemployment rate. (For example BIM - International Labour Office - uses the Holt method; it uses exponential data series with a linear trend; it is the method of estimating unemployment measured according to the criteria of the International Labour Office (National Institute of Statistics, 2011)). We propose a study of econometric methods used in estimating and predicting the unemployment data in Maramures through the open-source mathematical-statistical programming environment $R$, namely the regression method.

The linear regression, polynomial regression, spline regression and B-spline regression are used. The linear regression is particularly popular due to its ease of use and determines the line which passes through or adjacent to data points, based on the principle of least squares. But the linear regression and polynomial 
regression are not smooth enough to model real situations. The spline regression ensures flexibility in the estimation of the model. It is a mathematical-economic model adapted to changes in the economy which "keeps the continuity of the regression function, but splits the studied data in intervals with homogenous characteristics." (Geambasu et al, 2010). The B-Spline regression is also a flexible model that offers numerical stability to the algorithm and it is easy to implement. The comparative study of the four variants of these unemployment progressions are applied over a period of time (years).

\section{Literature review}

It is known that the regression is an econometric technique which investigates the relationship between a dependent and independent variable, "used for forecasting, time series modeling and finding the causal effect relationship between the variables." (Sunil, 2015) There are many forms of regressions. The challenge is to identify what regression best fits the problem investigated.

Linear regression was the first type of regression analysis and it is used widely in practical applications. The frequent economic changes highlight the necessity of adapting regression models to variation of the economy. This is the case of the spline regression model.

The spline regression is a relatively recently studied technique. In 1991, Friedman extended the recursive partitioning regression model of Morgan and Sonquist (1963) and Breiman, Friedman, Olshen and Stone (1984) by constructing a cumulative function which reunites the functions adapted to each sub-region, thus offering a better understanding of the evolution of the dependent variable. He applied the model to data sets from signal theory (numbers of shots), analytical chemistry (Portuguese olive oil) or artificial functions. Since then, specific economic problems were better solved by using the spline regression model. Thus Blindell, Chen and Kristensen (2007) studied the relation between the demand of goods and household budgets, using a continuous function on subsets of data resulted also from adding the subsets functions. Engle and Gonzalo (2008) studied the relation between the financial market and macroeconomic evolution using a GARCH-spline regression model for describing the trend with reduced frequency of macroeconomic variable volatility in time. Greiner (2009) used penalized splines to study the relation between the "primary surplus to GDP ratio and the debt ratio" (Greiner, 2009). Liu and Yang (2010) proposed the spline-backfiteed local linear procedure and applied it to a "varying coefficient extension of the Cobb-Douglas model for the US GDP that allows non neutral effects of the R\&D on capital and labor as well as on the Total Factor Productivity." Haupt, Kagerer and Steiner (2014) illustrate spline and B-spline regression in an empirical 
application using unit sales, retail prices and display activities on the store level from a food chain in Chicago. For the computations they used the open-source software R. Using spline regression and R, Shujie et al (2015) computed their results on GDP growth and OECD Status. The list doesn't stop here.

If the mentioned papers use $\mathrm{R}$ for the computation of the created spline regression models, the present paper reunites four of the regression models (linear, polynomial, slpine and B-spline) and implements an R-function which generates results specific to each regression. The function compares these results in order to help the users in applying the proper model. We illustrate the functionality of the implemented R-function using unemployment data from the Maramures County.

\section{Methodology}

One of the advantages of the $\mathrm{R}$ statistical environment is the fact that complicated mathematical definitions and formulae may be avoided. The $\mathrm{R}$ code doesn't require these.

The piecewise linear model is "a non-linearity captured by estimating a linear regression through several intervals" (Ruppert et al, 2003) and is given by the equation

where $\mathrm{a}_{\mathrm{i}}, \mathrm{b}_{\mathrm{i}}$ are the coefficients of the model.

$$
\mathrm{y}_{\mathrm{i}}=\mathrm{a}_{\mathrm{i}}+\mathrm{b}_{\mathrm{i}} \mathrm{x}+\varepsilon_{\mathrm{i}}, \text { if } \mathrm{x} \in\left[\mathrm{t}_{\mathrm{i}-1}, \mathrm{t}_{\mathrm{i}}\right], \mathrm{i}=1, \ldots, \mathrm{k},
$$

But the regression function is not smoothed at the knots $t_{1}, \ldots, t_{k-1}$. (Ruppert et al, 2003) Spline is a smooth piecewise regression model with transition at the knots. The cubic spline regression model is a continuous piecewise function with continuous second order derivatives:

$$
\mathrm{y}=\mathrm{a}+\mathrm{b}_{1} \mathrm{x}+\mathrm{b}_{2} \mathrm{x}^{2}+\mathrm{b}_{3} \mathrm{x}^{3}+\Sigma_{\mathrm{j}=1, \ldots, \mathrm{k}} \mathrm{b}_{\mathrm{j}+3}\left(\mathrm{x}-\mathrm{t}_{\mathrm{j}}\right)_{+}{ }^{3}+\varepsilon,
$$

where the notation ()$_{+}$is the mathematical notation for truncated power functions. The truncated functions often generate unstable numerical results. (Ruppert et al, 2003) The truncated basis is replaced by the B-spline basis which has compact support (i.e. values are equal to 0 outside two adjacent knots).

B-spline is a spline model smooth at the boundary knots expressed as a combination of basic B-spline functions (cubic B-spline):

$$
\mathrm{y}=\sum_{\mathrm{i}=1, \ldots, \mathrm{k}} \mathrm{b}_{\mathrm{i}} \mathrm{B}_{\mathrm{i}, 3}(\mathrm{x})+\varepsilon, \mathrm{x} \in[\mathrm{a}, \mathrm{b}] .
$$

These $\mathrm{B}$-spline basis functions $\mathrm{B}_{\mathrm{i}, 3}$ can be determined from the recurrent formula of Carl de Boor (Carl de Boor, 1972); this recurrent formula makes the algorithm easy to implement.

We use the pre-defined R-functions for regressions: 
Tilca M., Bojor M. (2016)

Comparative study on different types of regression applied to unemployment in Maramures County of Romania

Table 1. The R-functions used in regression models

\begin{tabular}{|l|l|l|}
\hline \multicolumn{1}{|c|}{ model } & \multicolumn{1}{c|}{ R-function } & \multicolumn{1}{c|}{ Interpretation } \\
\hline linear & $l \mathrm{~m}(\mathrm{Y} \sim \mathrm{X})$ & $\begin{array}{l}\text { the adequacy of the linear model having } \mathrm{Y} \text { as the } \\
\text { response variable and } \mathrm{X} \text { as predictor }\end{array}$ \\
\hline polynomial & $\mathrm{lm}(\mathrm{Y} \sim \mathrm{pol} \mathrm{I}())$. & $\mathrm{Y}$ is modeled linearly by $\mathrm{y}=\mathrm{a}+\mathrm{b}_{1} \mathrm{x}+\mathrm{b}_{2} \mathrm{x}^{2}$ \\
\hline spline & $\mathrm{lm}(\mathrm{Y} \sim \mathrm{nS}())$. & function to model $\mathrm{Y}$ by natural cubic spline function \\
\hline B-spline & $\mathrm{lm}(\mathrm{Y} \sim \mathrm{bs}())$. & function to model $\mathrm{Y}$ through cubic B-spline function \\
\hline
\end{tabular}

Source: adapted from R library and (Paradis, 2013)

$R$ is a free environment language and software for statistical calculation and graphics, developed since 1995 by Ross Ihaka and Robert Gentleman (hence the name R). It quickly gained the attention of programmers and statisticians becoming a powerful environment for statistical computing. $\mathrm{R}$ contains linear and non-linear statistical modeling techniques, statistical tests, techniques for linear time series analysis etc. $R$ is an integrated suite of software facilities for data manipulation, calculation, graphics display that includes a simple and effective programming language, allowing statistical techniques to be implemented. $\mathrm{R}$ is a case-sensitive dialect of the $\mathrm{S}$ language (S language is a statistical programming language, developed since 1975, and updated to its modern version since 1988.). The code may be placed in the Command prompt window or may be used from a source file. There are a variety of data types including vectors (numeric, character, logic), matrices, lists and data windows. R's functionality comes from the basic functions found in the dedicated $\mathrm{R}$ packages or from complex functions created by the user.

$\mathrm{R}$ provides facilities for implementing regressions through regression functions which are stored in packages distributed with the installation of $R$. A characteristic feature of $R$ is the regression model $l m(Y \sim$ model, data), where $Y$ is the analyzed response and model is a set of terms for which some parameters will be estimated. For the linear regression the model is considered to be the set of independent variables $\mathrm{X}$, the poly $($.$) model corresponds to the polynomial$ regression, the ns (.) model to the natural spline regression and the bs (.) model to the B-spline regression (see Table 1).

The source code function that includes these formulas was written in $\mathrm{R}$, in an editor file (New Script) and saved as Regression.R. The input data of the function (which has the same name: Regression) is the set of independent variables X, the set of dependent variables $Y$ and the $p$ value for which the prediction is intended. The output data is data specific to each regression, mainly the predicted values and the graphs of the regressions. The interpretation of the results is 
Tilca M., Bojor M. (2016)

Comparative study on different types of regression applied to unemployment in Maramures County of Romania

reported in the last part of the algorithm, Conclusions. Main steps of the algorithm are described below.

Table 2. Other R-functions used in the algorithm

\begin{tabular}{|c|c|}
\hline R-function & Used to \\
\hline cat $(" . . . ")$ & print the information on-screen \\
\hline cor.test $(\mathrm{X}, \mathrm{Y})$ & test the degree of correlation between two variables \\
\hline predict (.) & compute the estimated values for new data of the model \\
\hline plot (.) and abline (.) & $\mathrm{abline}$ function plots the regression line $\mathrm{y}=\mathrm{a}+\mathrm{bx}$ \\
\hline data.frame (.) & create a sequence of data saved as a table \\
\hline $\begin{array}{l}\text { predict }(., \text { interval } \\
=" \text { predict } ", \text { level }=.95)\end{array}$ & predict data with the $95 \%$ confidence \\
\hline summary (.) \$r.squared & $\begin{array}{l}\text { extract the R-squares coefficient; it specifies how much } \\
\text { the variation of } Y \text { is explained by the independent } \\
\text { variable }\end{array}$ \\
\hline summary (.) \$sigma & $\begin{array}{l}\text { extract the sigma value of the standard error; it specifies } \\
\text { how much the average observed values deviate from the } \\
\text { theoretical values }\end{array}$ \\
\hline $\begin{array}{l}\text { summary (.) \$fstatistic } \\
\text { and } \operatorname{pf}(.)\end{array}$ & $\begin{array}{l}\text { extract the p-value of the } \mathrm{F} \text { distribution; this value } \\
\text { determines whether the two variables are significantly } \\
\text { different by checking if the coefficient } \beta \text { is nonzero }\end{array}$ \\
\hline
\end{tabular}

Source: adapted from R library

Data input: $X, Y, p$

Data output:

Step I. For the linear regression

I.1. the coefficient of correlation between $X$ and $Y$

I.2. the linear regression coefficients $a, b$

I.3. the approximate values generated by the linear regression equation

I.4. errors (residue)

I.5. the predicted value for an independent variable $p$

I.6. the graph of the linear regression equation

Step II. For the polynomial regression

II.1. the quadratic polynomial coefficients

II.2. the predicted value for $p$

II.3. the predicted values generated by the polynomial regression

II.4. the errors (residue)

II.5. Plotting the polynomial curve

Step III. For the natural spline regression

III.1 the matrix of the cubic B-spline values for the natural spline function $n s($.$) function generates the matrix of order (card (X), df) of the B-$ spline basis function for a natural cubic spline ( $d f=5=>3$ inner knots) 
(card $(X)$ is the cardinal of $X$, equivalent to the length $(X)$ function in $R$, and df represents here the number of the degrees of freedom; for $n s($.$) function, the d f$ is given by $d f=$ internal knots no. $+1+1)$

III.2. the natural cubic spline regression coefficients

III.3. the predicted value by natural spline regression for known $p$

III.4. the errors (residue)

III.5. the spline regression curve graph

I ines (.) function takes the horizontal axis as the sequence seq(.)

of 200 points lying between the extremes of set $X$ and the vertical axix the set of the values predicted by the spline regression calculated in the abscissa points

Step IV. For the B-spline regression

$I V .1$. the matrix of the basic B-spline functions

bs (.) function generates the matrix of order (card (X), df) of the values of the B-spline basis functions for a polynomial spline function (cubic) ( $f f=5=>1$ inner knot) (We note that the number of the degrees of freedom df for the bs (.)function is given by df = internal knots no.+1+degree of the spline function)

$I V .2$. the cubic B-spline coefficients of the regression

$I V .3$. the predicted value of the $B$-spline regression for $p$

$I V .4$. the predicted values generated by B-spline regression for the observed variable $X$

IV.5. the errors (residue)

IV.6. the B-spline regression curve

Step $V$. Generating the conclusions

$V .1$. the values predicted by the 4 regressions for a given value

$V .2$. the prediction interval (The prediction interval represents all the predicted values between the observed values which are contained with a certain probability)

$V .3$. the errors generated by the 4 regressions

$V .4$. the $R$-Squared coefficient value for the 4 regressions

$V .5$. the standard error

V.6. the p-value

The applicability of this algorithm is highlighted by the study of regressions in the case of the unemployment data from Maramures County.

\section{Main findings}

The issue studied is the evolution of unemployed in Maramures County and its prediction in time. Yearly reports from the AJOFM database regarding the number of registered unemployed in 2000-2015 in Maramures County are used as statistical data. The method used here is the regression that uses the years 2000- 
2015 as the independent variable and the number of the unemployed from Maramures as the dependent variable. It is known that the number of the unemployed is influenced by a series of factors such as the number of job offers, the GDP and so on. For the sake of simplicity, the comparative study is applied for the observations of the annual unemployed number. Thus the study underlines the unemployment evolution through the linear regression, polynomial, spline and Bspline regression, using the algorithm described above.

The first step is to write the observed data (using a comma separator for data) and to save it in a text document (Notepad, WordPad, MS Word, s.o.) as a simple .txt file.

The sequence of instructions (Fig.A.1) reads the data from the file: setting the access path to the directory where the . txt file was saved $->$ reading the data from the file (in this case UnemloyedEvolution.txt) in the mandatory variable givendata $->$ viewing the data by calling givendata variable $->$ reading the independent variable Year in the $X$ mandatory variable $->$ reading the unemployedNo dependent variable in the $Y$ mandatory variable $->$ displaying $X$ and $Y$. The function source (Regression.R) calls the source code of the algorithm from the file Regression.R. The function Regression $(X, Y, 2011)$ applies the linear regression model, polynomial, spline and $\mathrm{B}$-spline for the variables $\mathrm{X}$ and $\mathrm{Y}$, and it performs the prediction for the independent variable 2011.

For each model the function returns the model coefficients, predicted/ theoretical values which are generated by the model for both an independent variable and for independent initial values, errors (residue) and the statistical parameters of the method ( $p$-value, the multiple R-squared coefficient, the adjusted R-squared, the residual standard error, the number of degrees of freedom, the significance coefficients). Results can be viewed in steps I-IV (see Fig.A.2 for polynomial regression), but the comparison and interpretation may be made easier by using the graphical representation (Figure 1) and the conclusions contained in Step V. The table 3 summaries the results contained in conclusions.

Table 3. The results generated by the algorithm in the case of the four regressions

\begin{tabular}{|c|r|r|r|r|l|r|}
\hline $\begin{array}{c}\text { Summary } \\
\text { Regressions }\end{array}$ & $\begin{array}{l}\text { Median } \\
\text { Residual }\end{array}$ & $\begin{array}{l}\text { Residual } \\
\text { standard error }\end{array}$ & $\begin{array}{l}\text { Multiple R- } \\
\text { squared }\end{array}$ & $\begin{array}{l}\text { Adjusted } \\
\text { R-squared }\end{array}$ & Coefficients & $\begin{array}{l}\text { Predicted value } \\
\text { for 2011 }\end{array}$ \\
\hline Linear & 368.2 & 2,950 & 0.4651 & 0.4269 & $\begin{array}{l}\text { Intercept: } \\
1,131,383.2 \\
\text { b: --558.3 }\end{array}$ & 8,656 \\
\hline $\begin{array}{c}\text { Quadratic } \\
\text { Polynomial }\end{array}$ & 710.2 & 2,539 & 0.6322 & 0.5756 & $\begin{array}{l}\text { Intercept: } \\
\text { b.302e+0.8 } \\
\text { b1: } \\
-3.284 \mathrm{e}+0.5\end{array}$ & 7,921 \\
\hline
\end{tabular}


Tilca M., Bojor M. (2016)

Comparative study on different types of regression applied to unemployment in Maramures County of Romania

\begin{tabular}{|c|c|c|c|c|c|c|}
\hline $\begin{array}{r}\text { Summary } \\
\text { Regresstons }\end{array}$ & $\begin{array}{l}\text { Median } \\
\text { Residual }\end{array}$ & $\begin{array}{l}\text { Residual } \\
\text { standard error }\end{array}$ & $\begin{array}{l}\text { Multiple R- } \\
\text { squared }\end{array}$ & $\begin{array}{l}\text { Adjusted } \\
\text { R-squared }\end{array}$ & Coefficients & $\begin{array}{l}\text { Predicted value } \\
\text { for } 2011\end{array}$ \\
\hline & & & & & $\begin{array}{l}\mathrm{b} 2: \\
8.165 \mathrm{e}+0.1 \\
\end{array}$ & \\
\hline $\begin{array}{l}\text { Cubic } \\
\text { Spline }\end{array}$ & 127.5 & 1,391 & 0.9236 & 0.8727 & $\begin{array}{l}\text { Intercept: } \\
-38,69 \\
\text { b1: } 38,774 \\
\text { b2: } 48,198 \\
\text { b3: } 44,442 \\
\text { b4: } 53,886 \\
\text { b5: } 21,044 \\
\text { b6: } 115,733 \\
\text { b7:lin.comb. }\end{array}$ & 10,820 \\
\hline $\begin{array}{l}\text { Cubic B- } \\
\text { spline }\end{array}$ & 52.95 & 1,673 & 0.9263 & 0.8158 & $\begin{array}{l}\text { Intercept: } \\
21,242 \\
\text { b1: }-4,467 \\
\text { b2: }-9,715 \\
\text { b3: }-10,093 \\
\text { b4: }-16,700 \\
\text { b5: }-8,888 \\
\text { b6: }-9,810 \\
\text { b7: }-15,565 \\
\text { b8: }-12,130 \\
\text { b9: }-14,017\end{array}$ & 10,144 \\
\hline
\end{tabular}

Source: own results adopted from Regression. R function

Figure 1. The graphical representation of the regressions applied to the annual unemployed number in Maramures

The REGRESSION reprezentations

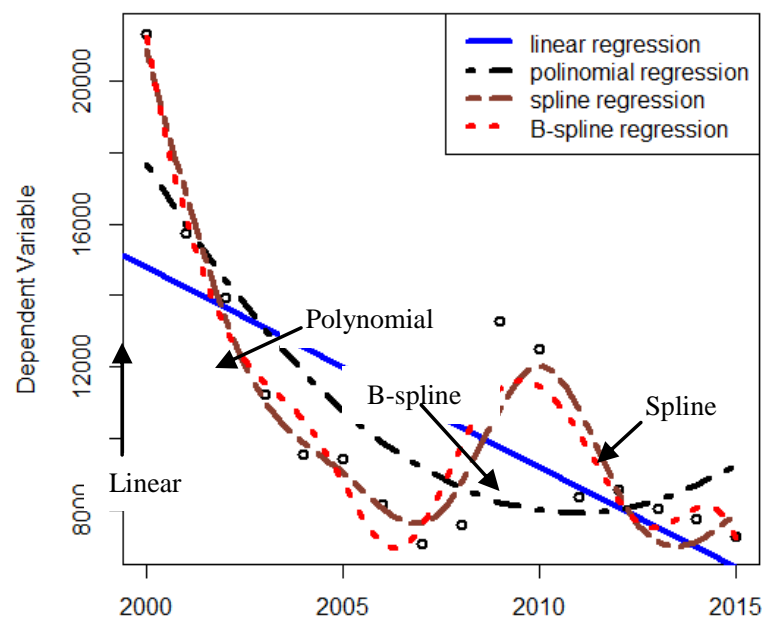

Source: own results generated by Regression. R function

DE GRUYTER OPEN 
The graphical representation (Figure 1) shows that the B-spline and spline regressions approximate the observed data more accurately than the linear regression and polynomial regression (see also Fig.A.5 for generated results). This is primarily due to the definition of the spline function. In the case of the unemployment in Maramures, the nonlinear manner of distribution of the observed data makes linear and polynomial regression to be discredited in the face of spline and B-spline regressions.

The theoretical values for periods of time within the 2000-2015 range differ as precision from one model to another. Thus, for a theoretical value for the number of unemployed in 2011, the linear regression is the method that sets the minimum error (Table 1 or Fig.A.3 for generated results) and for 2013 the optimum theoretical value is given by the spline regression. This result can be observed also from the analysis of the model that generates the lowest residue, as it is shown in conclusion 3 (Fig.A.5).

With a probability of $95 \%$, the number of unemployed in 2011, given by the linear regression, can oscillate between 2,024 and 15,289, a relatively broad range compared to the spline regression (Table 4 and Fig.A.4 for generated results).

Table 4. The predicted intervals (with a probability of $95 \%$ ) in which the theoretical value in 2011 is located

\begin{tabular}{|l|c|c||c|}
\hline \multirow{2}{*}{ Regression } & \multicolumn{2}{|c|}{ Prediction interval } & \multirow{2}{*}{ p-value } \\
\cline { 2 - 3 } & min & max & p-val \\
\hline Linear & 2,024 & 15,289 & 0.00361301 \\
\hline Polynomial & 2,136 & 13,707 & 0.00150077 \\
\hline Spline & 7,190 & 14,449 & 0.00014791 \\
\hline B-spline & 5,071 & 15,217 & 0.00879304 \\
\hline
\end{tabular}

Source: own results adopted from Regression. R function

Within the studied phenomenon, the comparative analysis of the residue shows that the spline regression model is valid. In order to identify which method can be used to a greater extent forecasters, the R-squared is compared. The B-spline regression can be used in predictions with $92.63 \%$ confidence interval (see Table 1 and Fig.A.6 for generated results).

The standard errors of the studied phenomena are relatively high in all four estimates (Table 1 and Fig.A.7 for generated results), which means that the average deviation of the observed values compared to the theoretical ones is high.

The predicted result with the lowest standard deviation of the estimation is given by the splines regression and has an error of $\pm 1,390$ unemployed.

The results investigated so far raise the question: is there a significant relationship between the amount of time (years) and the number of the unemployed? The null 
hypothesis test $\beta=0$ leads to p-values that are smaller than 0.05 , so the null hypothesis is rejected in all four cases, with a high degree of trust in the case of the spline regression ( $p$-value $=0.00014791$ ). See Table 4 and Fig.A.8.

The intensity of the relationship between the two variables $X$ and $Y$ is given by the correlation coefficient of linear regression model, namely -0.6819874 , the correlation being a relatively good, negative one, which emerges from the trend of the decreasing number of the unemployed.

For a future prediction, the function Regression $(X, Y, 2016)$ returns the predictions from Fig.A.9. and Table 5. The polynomial regression and B-Spline regression in the near future indicate an increase, and the linear regression and spline regression indicate a decrease. For immediate future predictors, the spline and B-spline regression predictions will take extremely large values, or even negative ones, which confirms the known outcome that the spline functions are used in interpolation problems rather than extrapolation. The spline regressions are useful for predictions in which the unknown $X$ values are within the range of the independent variables.

Table 5. The predicted regressions value for $\mathrm{x}=\mathbf{2 0 1 6}$

\begin{tabular}{|l|r|r|r|r|}
\hline Regression & linear & polynomial & spline & B-spline \\
\hline Predicted value for $\mathrm{p}=2016$ & 5,865 & 10,029 & 8,805 & 1,679 \\
\hline
\end{tabular}

Source: own results adopted from Regression. R function

\section{Discussions}

By applying the linear regression, polynomial regression, spline regression and Bspline regression to the real model of the unemployed number in Maramures, the generated results may be interpreted as follows:

1. The validity of the model: the spline regression and B-spline regression models are valid because they have the regression line closer to the observed values. Their validity alternates depending on the choice of the model's degree of freedom, i.e. the number of internal knots. The function implemented in R, Regression, uses the same number of intermediate knots (five) for both models. For one internal point $(d f=3$, respectively $d f=5)$, the B-spline regression is valid.

Figure 2. The code of the spline regression and B-spline regression with five internal knots $(d f=7$, respectively $d f=9)$

SplineRegressionNatural<-lm ( $\mathrm{Y} n \mathrm{~ns}(\mathrm{X}, \mathrm{df}=7$, intercept=T), data=givendata) fitBspline $<-\operatorname{lm}(Y \sim b s(X, d f=9)$, intercept=T, data=givendata)

Source: author's view 
2. The relevance of the equation: The spline and $\mathrm{B}$-spline regressions are the models which have the estimated equations with a high degree of confidence; these models alternating if a different number of degree of freedom is chosen.

3. The level of significance: all four regressions state that the relationship between the number of unemployed and the period of time is significant, with greater significance in the case of the spline regression.

4. The residue: the spline and $\mathrm{B}$-spline regressions ensure a variation of the theoretical dependent errors which is smaller than the observed dependent one.

5. The predictions: the spline and $\mathrm{B}$-spline regressions are more accurate in the case of predictions for independent values $\mathrm{X}$ within the range of observations, for example if the number of unemployed in a given year located between 2000 and 2015 is not known. To follow the future evolution of the unemployment, the spline and B-spline regressions tend to generate false values, unstable results outside the range of given values.

The spline and B-spline regressions prove a higher tracking power of trends resulted from empirical data, and provide better tracking of the evolution of data over time. Although the spline regression is a useful approach in describing the economic evolution of the studied event, there are pros and cons, depending on the researched topic and the desired results.

The researcher can apply the implemented function Regression.R to his own phenomena to generate the regression results.

\section{Conclusions}

Correct assessment of the evolution of annual unemployment is a constant concern for economists. Regressions are relatively easy to create and apply models giving very good results in estimations.

In this paper we apply regression techniques in employment analysis and we compare the results in the case of Maramures County.

The dataset comes from AJOFM and consist of the last 16 years (2000-2015) and the number of unemployed corresponding to these years. From this dataset we observe that after an increase of the number of unemployed in the crisis years (2009-2010), the number of unemployed decreases in time (2011-2015).

The graphical representation shows that the data is oscillating.

A linear or polynomial regression will not efficiently generate the evolution of the unemployment. Only in 2002 and 2011 are the estimations of the unemployed number closer to the observed values. The tails are less reliable than the central portion.

A spline and B-spline representation will fit the given data more accurately due to their flexibility in knots. The B-spline regression provides the best information

54 DE GRUYTER OPEN
Studia Universitatis "Vasile Goldis" Arad. Economics Series Vol 26 Issue 3/2016 ISSN: 1584-2339; (online) ISSN: 2285 - 3065

Web: publicatii.uvvg.ro/index.php/studiaeconomia.Pages $44-61$ 
about the evolution of the unemployed because B-spline knots are not restricted at the ends.

For investigations which include future prediction of the unemployment, we can use linear regression. In 2016 the number of the unemployed is estimated to be 5865. For investigations which include the evolution of the unemployment in past years, we can use spline and B-spline regression because they fit well the observed data. Setting five interior knots automatically selected by R: 2002.5, 2005, 2007.5, 2010, 2012.5, the entire interval is split into 6 sub-regions which can offer a better analysis of the unemployment trends in Maramures. Applying Regression $(X, Y, P)$ with $p=2012,2012.1, \ldots, 2012.5$ we obtain the unemployment evolution in the fifth sub-region.

Thus, the implemented function Regression unifies the regression results. Its application only requires entering data and using several commands calling the function $\mathrm{R}$. The graphic helps with observing the phenomenon. The challenge lies in interpreting the results. Spline and B-spline regressions explain the phenomenon within $\mathrm{X}$ very well and prove a higher power of tracking the trends.

\section{References}

1. Blundell, R., Chen, X. K. (2007). Semi-Nonparametric IV Estimation of ShapeInvariant Engel Curves. Econometrica, Vol. 75, No. 6 , pp. 1613-1669.

2. Breiman, L., Friedman, J. H., Olshen, R. A., Stone, C. J. (1984). Classification and regression trees. Wadsworth and Books/Cole, Belmont, CA.

3. de Boor, C. (1972). On calculating with B-splines. J. Approx. Theory, 6, pp 50-62.

4. Friedman, J. H. (1991). Multivariate Adaptive Regression Splines. The Annals of Statistics, Vol. 19, No. 1, pp. 1-67.

5. Geambasu, L., Jianu, I., Geambasu, C. (2010). Spline linear regression used for evaluating financial assets. Analele Universitaţii "Constantin Brâncusi" din Târgu Jiu, Seria Economie, $N$ r. 4/2010 , pp. 310-321.

6. Greiner, A. (2009). Estimating penalized spline regressions: theory and application to economics. Applied Economics Letters, 16, pp. 1831-1835.

7. Haupt, H., Kagerer, K., Steiner, W. (2014). Smooth quantile bases modeling of brand sales, price and promotional effects from retail scanner panels. Journal of Applied Econometrics, DOI 10.1016/j.jeconom.2014.06.003.

8. Liu, R., Yang, L. (2010). Spline-backfitted kernel smoothing of additive coefficient model. Econometric Theory 26, pp. 29-59.

9. Ma, S., Racine, J., Yang, L. (2015). Spline regression in the presence of categorical predictors. J. Appl. Econ. 30 , pp. 705-717.

10. Morgan, J. N., Sonquist, J. A. (1963). Problems in the analysis of survey data, and a proposal. J. Amer. Statist. Assoc. 58 , pp. 415-434. 
11. National Institute of Statistics. (2011). Unemployment BIM methodology on a monthly basis. Retrieved from www.insse.ro: www.insse.ro/.../Metodologia_rata\%20somaj\%20 BIM\%20lunar_rev.doc. Accessed 6 April 2016.

12. Paradis, E. (2013). $R$ for beginners. Retrieved from https://cran.rproject.org/doc/contrib/Paradis-rdebuts_en.pd. Accessed 6 Aplir 2016.

13. Cambridge Series in Statistical and Probabilistic Mathematics, volume 12, Cambridge University Press.

14. Ruppert, D., Wand, M., Carroll, R. (2003). Semiparametric regression. New York: Cambridge University Press.

15. Sunil, R. (2015). 7 tipes of regression techniques you should know! Retrieved from Analytics Vidhya: http://www.analyticsvidhya.com/blog/2015/08/comprehensive-guideregression/. Accesed 12 April 2016.

16. Vlad, C., Brezeanu P., Fiscality - a relevant factor influencing regional development in Romania and the European Union, Studia Universitatis "Vasile Goldis" Arad Economics Series, Vol. 26, Issue 2/2016, pp 48-62.

17. Wu, W. (2009). An application of spline regression to dose-response analysis in observational study. Retrieved from https://medschool.vanderbilt.edu/cqs/files/ cqs/media/2009Jan16William.pdf. Nashville - Vanderbilt University Medical School, USA. Accesed 13 April 2016.

\section{Appendices}

Appendix A. The interpretation of the results generated by the implemented Rfunction Rgegression. $R$

Fig.A.7. The steps of reading the yearly unemployed number from the file UnemployedEvolution. txt

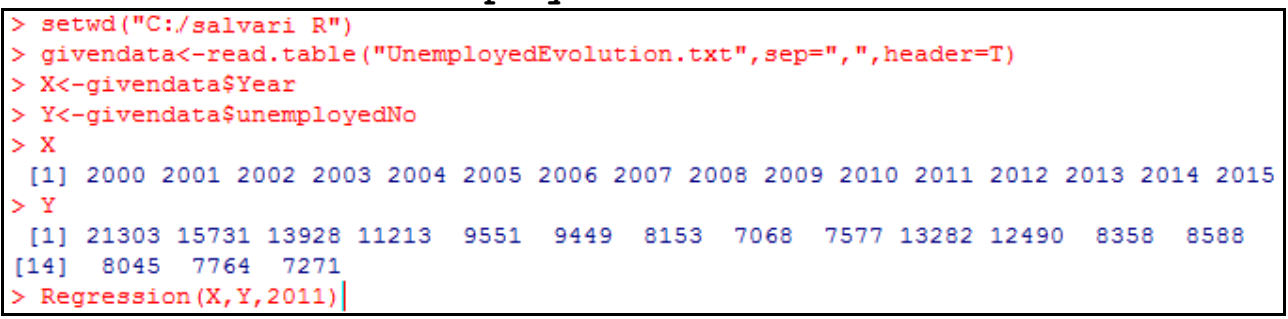

Source: own results generated by Regression. R function 
Tilca M., Bojor M. (2016)

Comparative study on different types of regression applied to unemployment in Maramures County of Romania

Fig.A.4. The predicted intervals in which theoretical value in 2011 is located, with a probability of $95 \%$

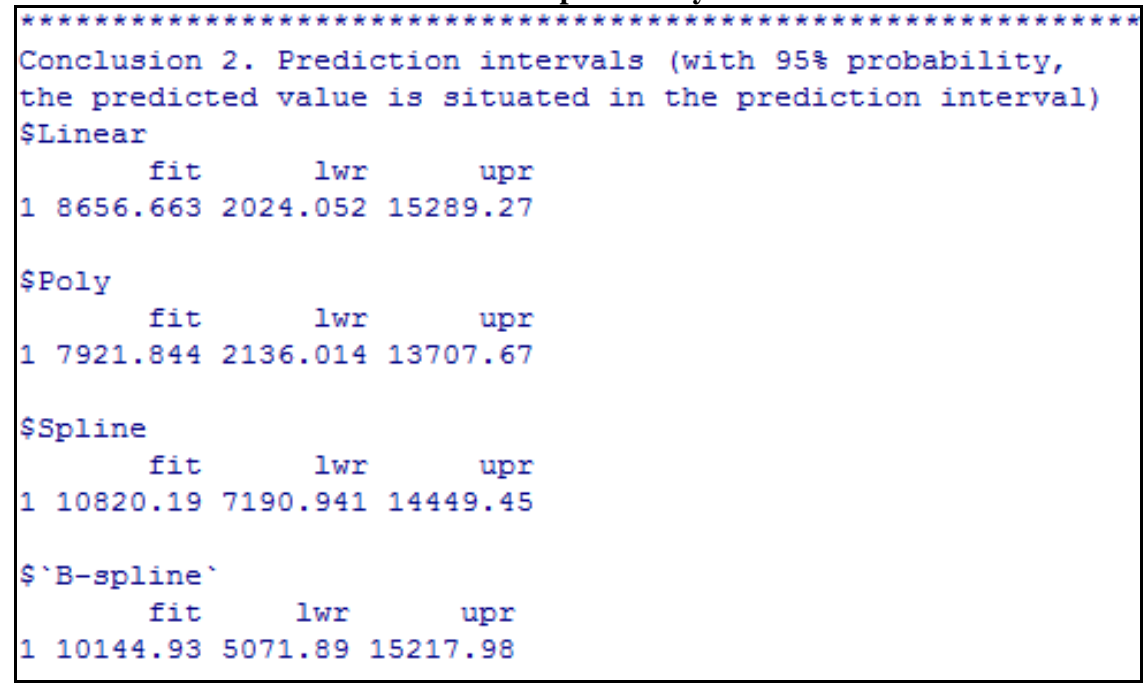

Source: own results generated by Regression.R function

Fig.A.5. Comparing the residue generated by the four models

\begin{tabular}{|lrrrr|}
\hline \multicolumn{7}{|c}{ Conclusion 3. Residuals: The residuals regressions values are: } \\
1 & Linear & Polynomial & Spline & B-spline \\
2 & 6505.1176 & 3647.4890 & 465.00869 & 60.64202 \\
3 & 1491.4103 & -223.1669 & -1053.33261 & -401.41916 \\
4 & -1910.0044 & -1828.3579 & 147.58528 & -366.54990 \\
5 & -3013.7118 & -2278.8930 & -334.52426 & -976.11918 \\
6 & -2557.4191 & -1332.7211 & 409.13011 & 720.30670 \\
7 & -3295.1265 & -1743.8423 & 107.39541 & 1066.91021 \\
8 & -3821.8338 & -2107.2566 & -558.08263 & -477.84617 \\
9 & -2754.5412 & -1039.9640 & -1164.93726 & -2165.75905 \\
10 & 3508.7515 & 5060.0356 & 2406.43907 & 1863.77601 \\
11 & 3275.0441 & 4499.7421 & 458.89477 & 1042.97199 \\
12 & -298.6632 & 436.1556 & -2462.19381 & -1786.93387 \\
13 & 489.6294 & 571.2759 & 46.57633 & 267.40466 \\
14 & 504.9221 & -229.8967 & 936.64403 & 546.97844 \\
15 & 782.2147 & -932.3625 & 635.36946 & -299.42887 \\
16 & 847.5074 & -2010.1213 & -632.96583 & 45.26240 \\
\hline
\end{tabular}


Tilca M., Bojor M. (2016)

Comparative study on different types of regression applied to unemployment in Maramures County of Romania

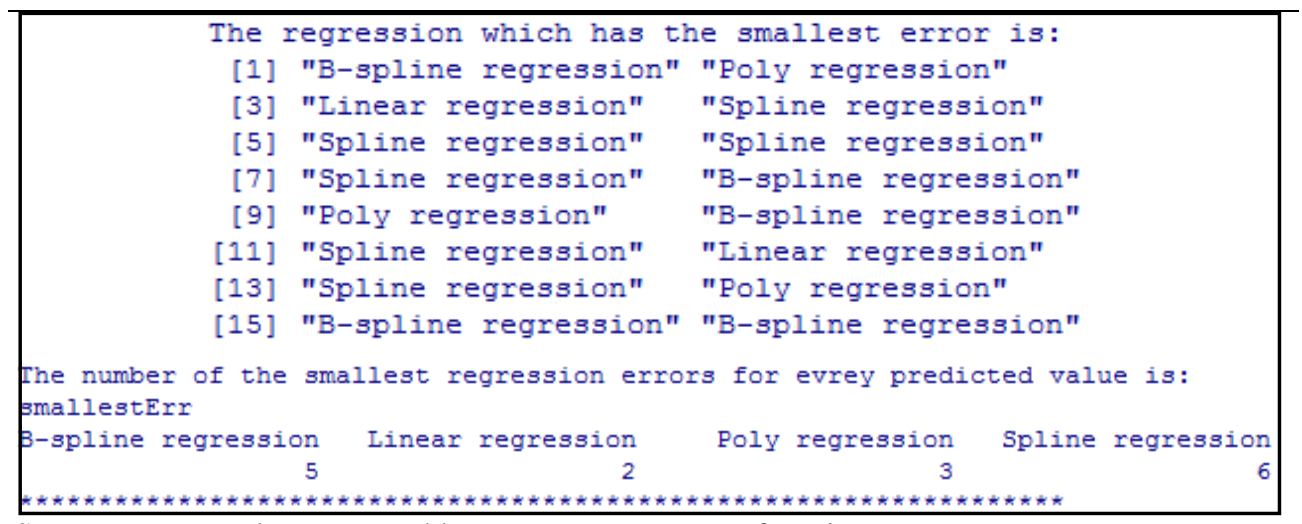

Source: own results generated by Regression. R function

Fig.A.6. The R-squared in the case of regressions for the annual number of unemployed

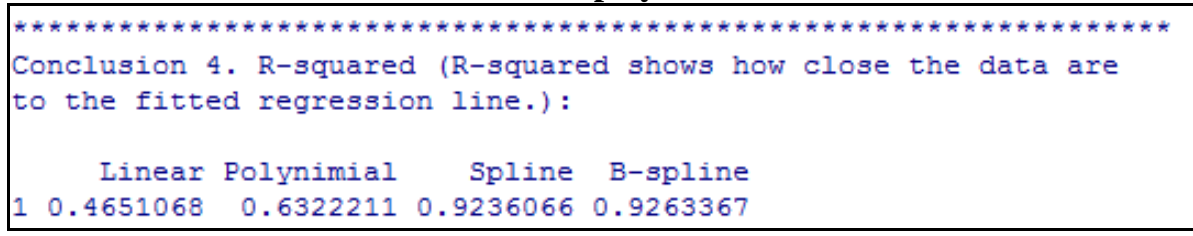

Source: own results generated by Regression. R function

Fig.A.7. The standard errors of the estimates given by the regressions

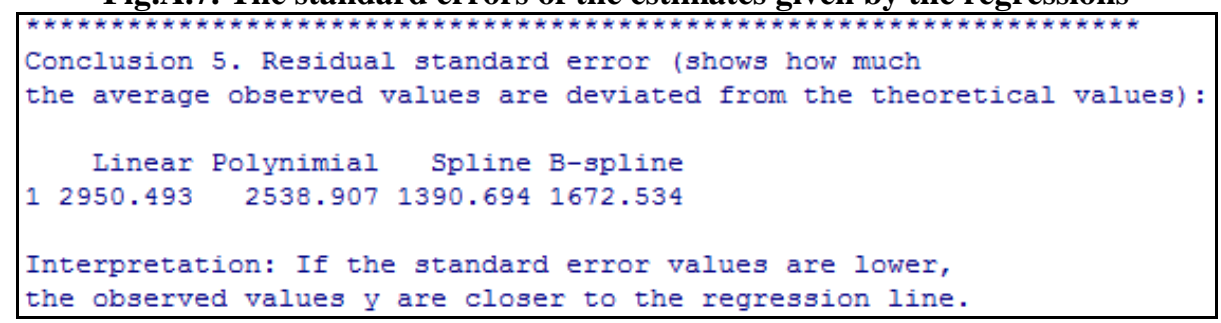

Source: own results generated by Regression. R function 
Tilca M., Bojor M. (2016)

Comparative study on different types of regression applied to unemployment in Maramures County of Romania

Fig.A.8. The exact level of significance given by the regressions regarding the yearly number of unemployed

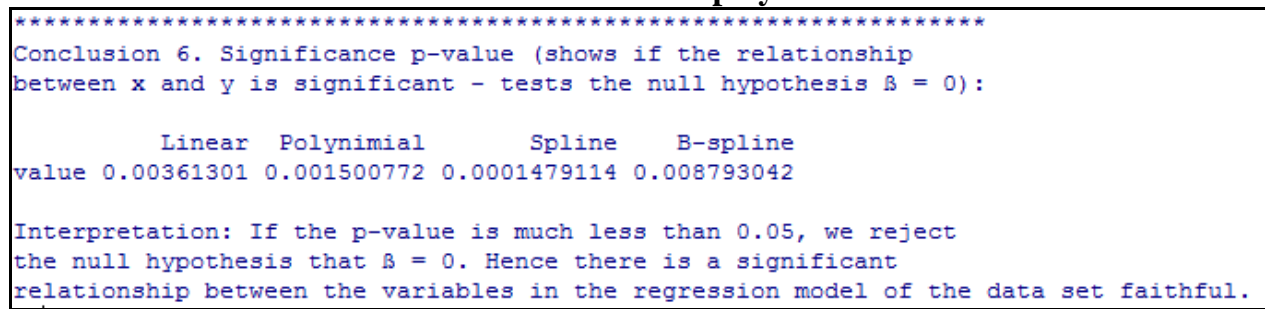

Source: own results generated by Regression. R function

Fig.A.9. The predicted regressions value for $x=2016$

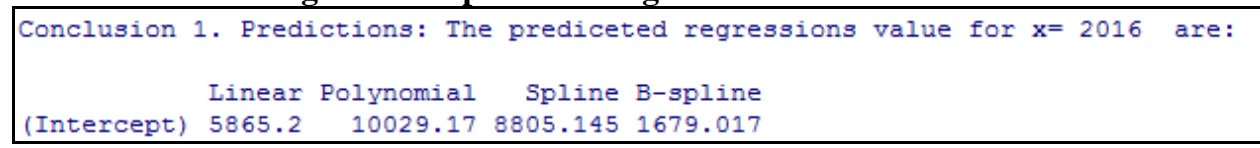

Source: own results generated by Regression. R function

\section{Apendix B. Sample R code}

The source code of the linear regression computation - excerpt

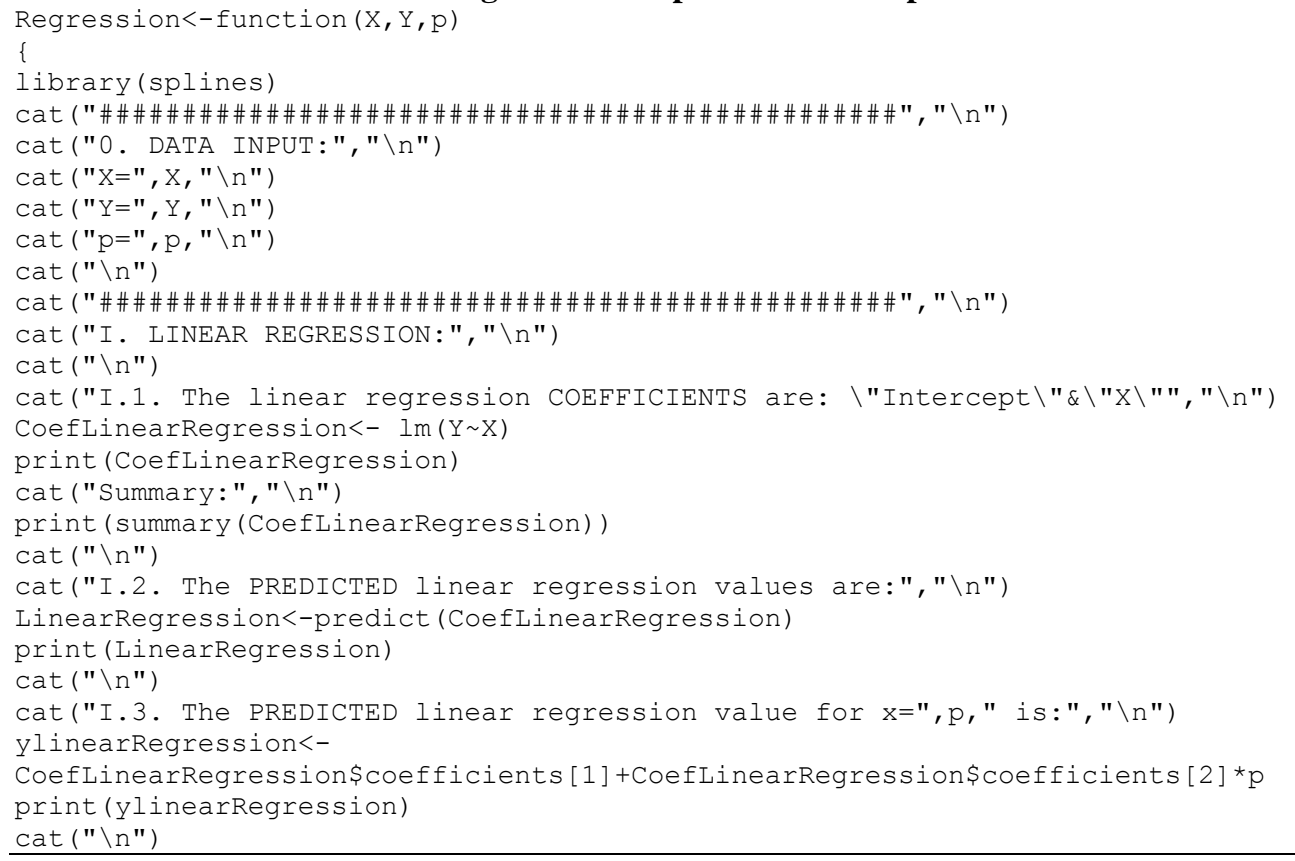


Tilca M., Bojor M. (2016)

Comparative study on different types of regression applied to unemployment in Maramures County of Romania

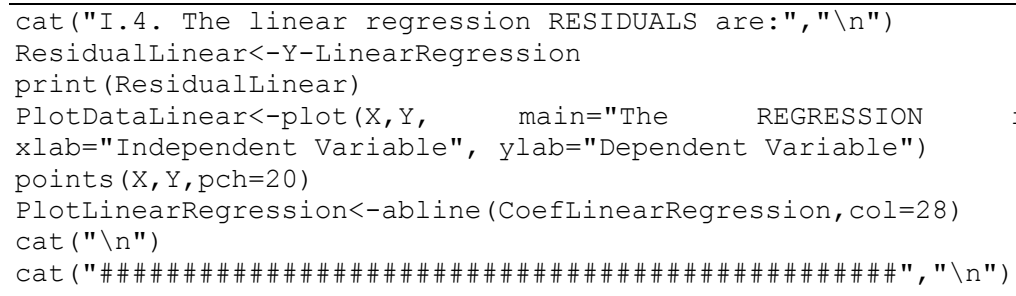

\section{The source code for computation of the residuals and its frequency - excerpt}

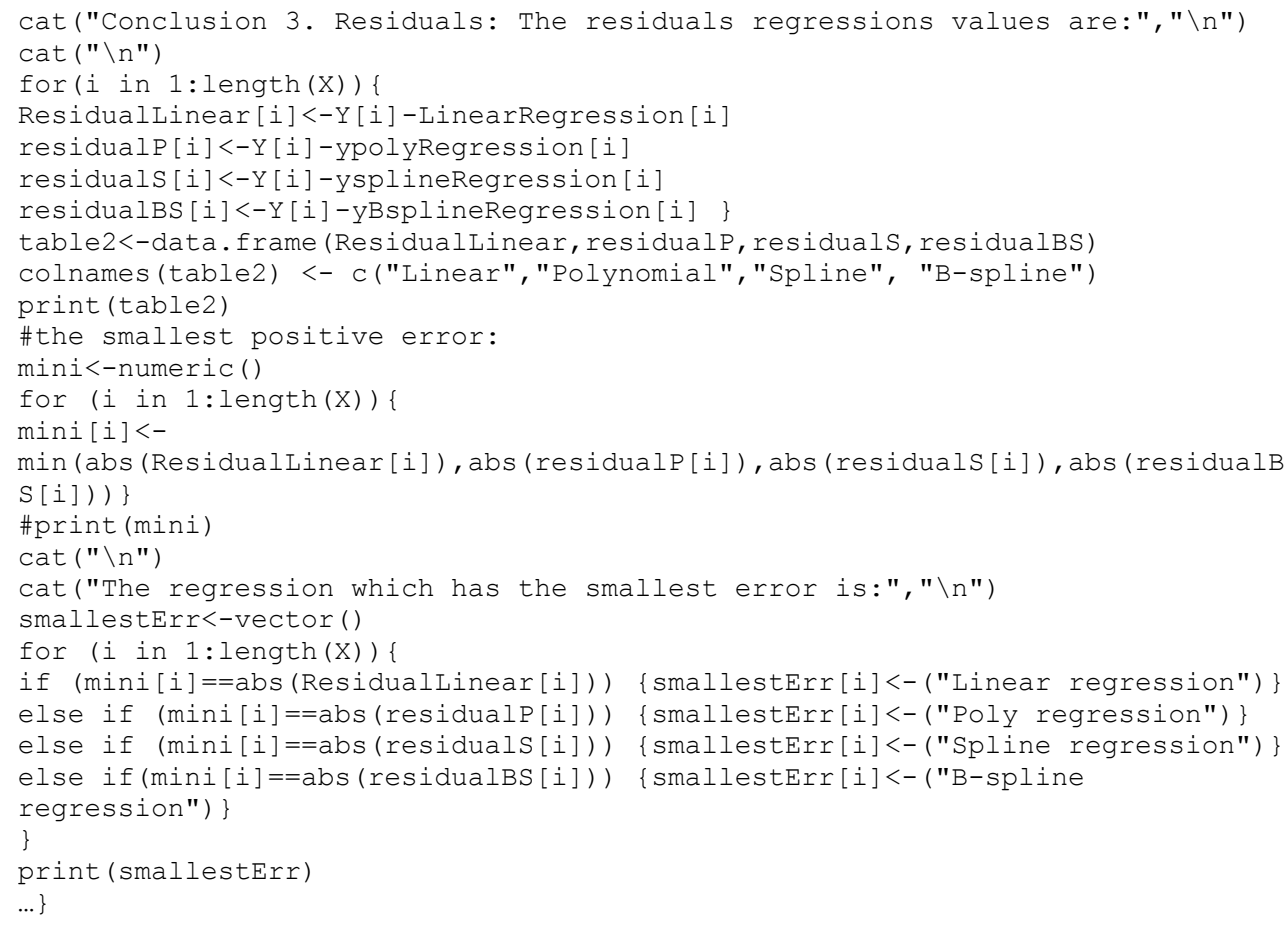

